\title{
Commentary
}

\section{One bump, two bumps, three bumps, four? Using retrieval cues to divide one autobiographical memory reminiscence bump into many}

\author{
David C. Rubin ${ }^{\mathrm{a}, \mathrm{b}, *}$ \\ a Duke University, USA \\ ${ }^{\mathrm{b}}$ Aarhus University, Denmark
}

\section{A R T I C L E I N F O}

\section{Article history:}

Received 9 December 2014

Received in revised form

23 December 2014

Accepted 23 December 2014

Available online 27 January 2015

\section{Keywords:}

Autobiographical memory

Reminiscence bump

Lifespan

Cued recall

The cues used to elicit autobiographical memories affect the proportion of memories in the bump (e.g., Rubin \& Schulkind, 1997a, Figure 3). Koppel and Berntsen (2015) demonstrate that these cues also affect the temporal location of the bump. No one has supported this observation so strongly or used it so thoroughly to probe the theoretical understanding of the bump. Koppel and Berntsen (2015) concentrate on understanding why the bump for important memories occurs when it does. They are less concerned about the bump for word-cued memories, proposing a search based on 'associative processes' to explain its location. This is an extremely non-specific mechanism that has been used to refer to involuntary retrieval (Berntsen, 2009, 2010). I step back from this dichotomy and claim that all autobiographical memories are the result of some retrieval processes and ask about those processes. I accept the Koppel and Berntsen (2015) life-script account for the important memories and concentrate on word and other cues, especially non-verbal sensory cues, that might help clarify the role of cuing autobiographical memories in general and be applied to understanding the difference in the peak age of the bump.

\footnotetext{
* Correspondence to: Department of Psychology and Neuroscience, Box 90086, Durham, NC 27708-0086, USA. Tel.: +1 919660 5732; fax: +1 9196605726.

E-mail address: david.rubin@duke.edu
}

\section{One bump}

The original demonstration of the reminiscence bump as a distinct autobiographical memory phenomenon sprang from research on memories cued by words. Koppel and Berntsen (2015) divide the bump into two bumps with different locations: one for wordcued and one for important memories. I begin my commentary by placing their findings in an historical context.

In 1974, Crovitz and Schiffman plotted the log of the number of word-cued autobiographical memories per hour on the $y$-axis and the log of the number of hours since the event occurred on the $x$-axis and obtained a straight line fit. Correlations of the fit to this power function were routinely above .95 and there was no control over learning or anything else except the cues (Rubin, 1982). Rubin, Wetzler and Nebes undertook an analysis of how the slope of the retention function would change with the age of the subject. Other researchers also were interested in and had data on the age distribution of the word-cued memories of older adults. Franklin and Holding (1977) and Fitzgerald and Lawrence (1984) had noted that the log-scale plots distorted the lifespan of older adults. In particular, equal ratios take up equal distance on the plot, thus for older adults the period from 1 to 6 hours occupies the same length as 1-6 days and 10-60 years, thereby severely compressing the early part of their lives.

Fitzgerald and Lawrence (1984, p. 695) found that "The one area of discrepancy between the predicted [power] function and the actual data occurs for the older sample. Rather than continuing to decline, the rate of memories per hour leveled off. Thus, the rate 
of memories per hour for events that are 60 years old is roughly the same as that for memories 20 years old." Because of these concerns, in addition to using log scales, Rubin et al. (1986) also used linear scales. On the linear plot, we did not find a monotonically decreasing retention function, but we did not have enough data to clearly characterize the increase. Therefore, we asked Holding, Fitzgerald, and Squire if we could combine data from their published papers with our own data.

We published our findings using the name "bump" because that was what appeared on the plot: a messy increase in memories with no clear theoretical explanation (Rubin, Wetzler, \& Nebes, 1986). By comparison, the retention function of Crovitz and Schiffman (1974) was extremely precise for the most recent 10 or more years of a person's life. Childhood amnesia was also fairly precise (e.g., Rubin, 2000). In our 1986 chapter, we drew the bump as a monotonically increasing component that added to the retention function, leaving the overall distribution's decrease at earlier ages to be accounted for by the childhood amnesia function (Figure 12.6, p. 219). That is, the bump was not defined by a theory but by the subtraction of two empirically fit functions from an observed distribution. We included the bump component only for adults over 40; empirically, with word cues, the retention and childhood amnesia components were much more powerful and prevented any chance of observing the bump in younger adults even if it were there. For a review of what happened next, see Koppel and Berntsen (2015).

A paper included in the Koppel and Berntsen (2015) review makes the claim that "the reminiscence bump was first observed by Franklin and Holding (1977; see too Fitzgerald \& Lawrence, 1984) and in a meta-analysis further explored and originally named by Rubin and colleagues (Rubin et al., 1986)" (Conway, Wang, Hanyu, \& Haque, 2005, p. 740). I wish to correct this misinformation. Rubin et al. (1986) combined and reanalyzed data from four sources in a new way that allowed the bump to be observed, it was not a metaanalytic combination of results reported earlier. Although both of the papers mentioned in the quote were innovative, important, and contained data we used for the discovery of the bump, neither presented results that could have allowed the bump to be observed.

Faced with the highly skewed distribution of autobiographical memories over the lifespan, Franklin and Holding (1977) made and clearly articulated the reasonable choice of using only one memory per subject for their analyses: the memory with the median age. Because even the median ages were not distributed normally, their figure shows the medians from individual subjects as distributions in addition to plotting the mean of the medians. To see the bump they would have had to pool the individual memories across subjects. Moreover, at a theoretical level, the main point of their paper was arguing against the assertion that "older persons tend to 'live in the past"' (p. 527). In support of their claim, their figure shows a straight line increase of the mean of the medians of remembered age as a function of chronological age. The Fitzgerald and Lawrence (1984) paper, cited by Conway et al. (2005), did two kinds of analysis. One used each subject's median age, as did Franklin and Holding; the other used log intervals, so neither method could have shown the bump.

\section{Cuing matters}

There are many forms of cuing and thus many variations of the retrieval processes that have been used and that can be used to help understand the temporal distribution of autobiographical memories. Koppel and Berntsen (2015) concentrate on word-cued and important memories and restrict their review to behavioral data. However, we know something about the location and time course of the neural processes used for retrieving word-cued autobiographical memories (Daselaar et al., 2008). Thus, we are in a position to begin to understand the issues Koppel and Berntsen (2015) raise at multiple levels of analysis. Schlagman, Kliegel, Schulz, and Kvavilashvili (2009) studied involuntary memory in older adults. Because there were no explicit cues for the involuntary memories, they were not included in Koppel and Berntsen (2015). However, they had the same temporal distribution as word-cued memories and so using associative processes mechanism for both as Koppel and Berntsen (2015) and Berntsen (2009, 2010) suggest, though vague, works empirically. According to Koppel and Berntsen (2015), using time periods, such as in the last ten years or when you were in grade school, produces mixed results and at a theoretical level can be seen as adding its own search processes (Friedman, 1993; Rubin \& Baddeley, 1989). This might introduce complexity that, given our current level of understanding, is not yet useful in trying to understand the mechanisms of search. There are also effects of cuing that were not examined because they were not central to the claims Koppel and Berntsen (2015) were making. Thus, we also know that words that are easier to image produce memories from an earlier age (Rubin, 1980; Rubin \& Schulkind, 1997b). An added complication is that a bump also exists for semantic information (Rubin, Rahhal, \& Poon, 1998). However, its location may vary considerably with the semantic domain and thus it may require considerable effort to provide results that could clarify the retrieval processes used in autobiographical memory.

Differences in the peak of the bump with changes in the cuing and retrieval processes have important theoretical implications. Such differences in the location of the peak cannot be explained purely in terms of encoding, which is one class of explanation we have suggested (Rubin et al., 1986, 1998) and the main theoretical mechanism in many other theories especially those that view adolescence and early adulthood as times of identity formation or increased cognitive ability (e.g., Conway \& Pleydell-Pearce, 2000; Fitzgerald, 1988; Holmes \& Conway, 1999; Janssen, Kristo, Rouw, \& Murre, 2015; see Koppel \& Berntsen, 2015, for a discussion).

\section{Two bumps, three bumps, four?}

In Koppel and Berntsen (2015) there are four papers that include both olfactory cues and the word cues that serve as labels for the olfactory cues; however, only the word-cued memories are included in the review. All four papers have the same conclusion about the location of the bump: for word cues the bump peaks at a time consistent with Koppel and Berntsen's (2015) conclusions with the most memories in the 11-20 decade, whereas for odor cues, the bump is earlier with most memories in the 0-10 decade (Chu \& Downes, 2000; Willander \& Larsson, 2006, 2007, 2008). In three of these studies the odor cues were the sensory cues of the odors themselves. In one (Willander \& Larsson, 2008), participants were requested to imagine the odor given the corresponding word cue. Then, they were asked to retrieve a memory to the imagined odor. The agreement among the four studies is striking and requires consideration.

Olfaction differs from other senses in many ways, especially in its neural structure (for a review with respect to autobiographical memory, see Rubin, 2006). However, when a request to imagine an odor rather than to actually sense one is used as the cue, many of these differences disappear. The language-based word cue for the odor to imagine does not bypass the neural structures that word cues rely on in the same way that odors do, nor does it have the direct preconscious link to emotions that odors do. In addition, producing a vivid image of an odor is more difficult than producing a visual image for the same object. My speculation is that word cues initiate a search that involves looking for a language-based context for the event, which becomes a narrative and then a specific scene that fits the narrative (Rubin \& Umanath, 2015). Similarly, requests 
for important memories would further increase search processes based on narrative. In contrast the imagined odor leads to a wider variety of scenes, some of which have less of a narrative context. But this is just speculation until data on the actual memories are examined in more detail.

In contrast, pictures, which Willander and Larsson (2006) found to be more similar to words in their temporal distribution, narrow the possible memories that could occur. The smell of coffee can be coffee in your own mug at home, in a cup on a saucer at an expensive restaurant, or in a Styrofoam cup at a takeout counter. A picture of coffee with no container is hard to see as coffee, but a picture that has coffee in one of these containers fits only one of these situations (see Rubin, Groth, \& Goldsmith, 1984 for a fuller discussion). This restricts the search and could increase language and narrative based attempts to understand the visual context. Olfaction is just one sensory cue that can lead to autobiographical memories; except for pictures and music (e.g., Rubin et al., 1984; Schulkind, Hennis, \& Rubin, 1999), few other types of sensory cues have been studied. This seems like the next logical place to expand Koppel and Berntsen's claims about the distribution of autobiographical memories.

\section{References}

Berntsen, D. (2009). Involuntary autobiographical memories. An introduction to the unbidden past. Cambridge, England: Cambridge University Press.

Berntsen, D. (2010). The unbidden past: Involuntary autobiographical memories as a basic mode of remembering. Current Directions in Psychological Science, 19, $138-142$.

Chu, S., \& Downes, J. J. (2000). Long live Proust: The odour-cued autobiographical memory bump. Cognition, 75, B41-B50.

Conway, M. A., \& Pleydell-Pearce, C. W. (2000). The construction of autobiographical memories in the self-memory system. Psychological Review, 107, 261-288.

Conway, M. A., Wang, Q., Hanyu, K., \& Haque, S. (2005). A cross-cultural investigation of autobiographical memory: On the universality and cultural variation of the reminiscence bump. Journal of Cross-Cultural Psychology, 36, 739-749.

Crovitz, H. F., \& Schiffman, H. (1974). Frequency of episodic memories as a function of their age. Bulletin of the Psychonomic Society, 4, 517-518.

Daselaar, S. M., Rice, H.J., Greenberg, D. L., Cabeza, R., LaBar, K. S., \& Rubin, D. C. (2008). The spatiotemporal dynamics of autobiographical memory: Neural correlates of recall, emotional intensity, and reliving. Cerebral Cortex, 18, 217-229.

Fitzgerald, J. M. (1988). Vivid memories and the reminiscence phenomenon: The role of a self narrative. Human Development, 31, 261-273.
Fitzgerald, J. M., \& Lawrence, R. (1984). Autobiographical memory across the lifespan. Journal of Gerontology, 39, 692-699.

Franklin, H. C., \& Holding, D. H. (1977). Personal memories at different ages. Quarterly Journal of Experimental Psychology, 29, 527-532.

Friedman, W. J. (1993). Memory for the time of past events. Psychological Bulletin, 113, 44-66.

Holmes, A., \& Conway, M. A. (1999). Generation identity and the reminiscence bump: Memory for public and private events. Journal of Adult Development, 6, 21-34.

Janssen, S. M. J., Kristo, G., Rouw, R., \& Murre, J. M. J. (2015). The relation between verbal and visuospatial memory and autobiographical memory. Consciousness and Cognition, 31, 12-23.

Koppel, J. M., \& Berntsen, D. (2015). The peaks of life: The differential temporal locations of the reminiscence bump across disparate cueing methods. Journal of Applied Research in Memory and Cognition, http://dx.doi.org/10.1016/ j.jarmac.2014.11.004 [in press]

Rubin, D. C. (1980). 51 properties of 125 words: A unit analysis of verbal behavior. Journal of Verbal Learning and Verbal Behavior, 19, 736-755.

Rubin, D. C. (1982). On the retention function for autobiographical memory. Journal of Verbal Learning and Verbal Behavior, 21, 21-38.

Rubin, D. C. (2000). The distribution of early childhood memories. Memory, 8 , 265-269.

Rubin, D. C. (2006). The basic-systems model of episodic memory. Perspectives on Psychological Science, 1, 277-311.

Rubin, D. C., \& Baddeley, A. D. (1989). Telescoping is not time compression: A model of the dating of autobiographical events. Memory and Cognition, 17, 653-661.

Rubin, D. C., Groth, L., \& Goldsmith, D. J. (1984). Olfactory cuing of autobiographical memory. American Journal of Psychology, 97, 493-507.

Rubin, D. C., Rahhal, T. A., \& Poon, L. W. (1998). Things learned in early adulthood are remembered best. Memory \& Cognition, 26, 3-19.

Rubin, D. C., \& Schulkind, M. D. (1997a). Distribution of important and word-cued autobiographical memories in 20-, 35-, and 70-year-old adults. Psychology and Aging, 12, 524-535.

Rubin, D. C., \& Schulkind, M. D. (1997b). Properties of word cues for autobiographical memory. Psychological Reports, 81, 47-50.

Rubin, D. C., \&Umanath, S. (2015). Event memory: A theory of memory for laboratory, autobiographical, and fictional events. Psychological Review, 122, 1-23.

Rubin, D. C., Wetzler, S. E., \& Nebes, R. D. (1986). Autobiographical memory across the adult lifespan. In D. C. Rubin (Ed.), Autobiographical memory (pp. 202-221). Cambridge, UK: Cambridge University Press.

Schlagman, S., Kliegel, M., Schulz, J., \& Kvavilashvili, L. (2009). Differential effects of age on involuntary and voluntary autobiographical memory. Psychology and Aging, 24, 397-411.

Schulkind, M. D., Hennis, L. K., \& Rubin, D. C. (1999). Music, emotion and autobiographical memory: They're playing your song. Memory E' Cognition, 27, 948-955.

Willander, J., \& Larsson, M. (2006). Smell your way back to childhood: Autobiographical odor memory. Psychonomic Bulletin \& Review, 13, 240-244.

Willander, J., \& Larsson, M. (2007). Olfaction and emotion: The case of autobiographical memory. Memory \&' Cognition, 35, 1659-1663.

Willander, J., \& Larsson, M. (2008). The mind's nose and autobiographical odor memory. Chemosensory Perception, 1, 210-215. 